International Journal of Technology 12(1) 43-53 (2021)

Received May 2020 / Revised July 2020 / Accepted November 2020

International Journal of Technology

http://ijtech.eng.ui.ac.id

\title{
Modular Isolation Units for Patients with Mild-to-Moderate Conditions in Response to Hospital Surges Resulting from the COVID-19 Pandemic
}

\author{
Yandi Andri Yatmo ${ }^{1 *}$, Mochammad Mirza Yusuf Harahap ${ }^{1}$, Paramita Atmodiwirjo ${ }^{1}$ \\ ${ }_{1}^{1}$ Department of Architecture, Faculty of Engineering, Universitas Indonesia, Kampus UI Depok, Depok \\ 16424, Indonesia
}

\begin{abstract}
This paper presents a design proposal of an Isolation Recovery House (IRH), an adaptable modular isolation care unit specifically designed for patients with mild-to-moderate conditions as a response to an infectious disease outbreak. In particular, the study responds to the current COVID19 pandemic, which urges the installation of isolation facilities as quickly as possible. The study offers a design solution that could expand the capacity for isolation facilities, especially in underdeveloped or developing countries, such as Indonesia, with many regions located further away from big cities. The design proposal assists existing hospitals in reducing excessive workload due to the surge in patients and control possible in-hospital transmission. The study began by investigating criteria for designing and constructing quickly-built isolation facilities that comply with the standards for isolation space, particularly COVID-19 patients. The criteria, namely quick construction, adaptability to various contexts, and meets the minimum isolation space design standards, formed the basis for proposing the IRH design. This paper argues that as a ready-toimplement design, IRH could be an option to improve health-care services during the pandemic.
\end{abstract}

Keywords: Adaptable; Isolation space design; Modular; Pandemic

\section{Introduction}

Since its declaration as a pandemic, COVID-19 has brought an enormous workload to hospitals around the world. A pandemic increases the need for intensive isolation spaces, where all admitted patients can be closely monitored and treated based on their conditions (Mitchell et al., 2017). Hospitals' ICUs, however, are typically designated for patients with severe conditions even though patients with mild-to-moderate conditions must still be isolated as well-whether they are in the recovery phase or an early phase of infection (Phua et al., 2020) - to make sure that there is no further unwanted transmission. This study presents a plausible design proposal as an alternative application of technology (Suwartha et al., 2017) that addresses the aspects of isolation space facilities in the pandemic.

Several approaches have been applied to meet the need for isolation spaces, including the adaptation of existing spaces within hospital buildings (Valipoor et al., 2020), the alteration of existing structures with vast space, such as stadiums and exhibition spaces (Yuen et al., 2012; Chen and Zhao, 2020), and the installation of new isolation units (Mo, 2020). However, when it comes to hospitals or health-care facilities in regions far away

${ }^{*}$ Corresponding author's email: yandiay@eng.ui.ac.id, Tel.: +62-813-82790386; Fax: +62-21-7863514 doi: 10.14716/ijtech.v12i1.4115 
from large cities, there is a concern regarding their capacity to provide such additional isolation spaces as there are less resources compared to hospitals located in larger cities or other more resourceful areas (Nwanya et al., 2016; Blavin and Arnos, 2020). This study explores the potential of a modular design to be implemented in such a situation.

\section{Methods}

The study was conducted through an evidence-based design approach, in which design decisions were based on evidence from research and project evaluation (Stichler and Hamilton, 2008). The IRH design presented in this study is the result of comprehensive reviews of the current literature that look closely at physical aspects crucial to the healthcare facility, in general, and the isolation space, including spatial layout, visual environment, ventilation and air circulation, and construction materials (Becker and Parsons, 2007; Ulrich et al., 2008). The study was conducted in three stages: (1) Reviewing various approaches for designing isolation space in response to the pandemic situation. The focuses of this review were the strategies for increasing hospitals' capacities and the modular construction approach as a promising method for achieving quick construction; (2) Reviewing the criteria for isolation space. Our extensive review covers the isolation room types, standards for air circulation, and design strategies for responding to the possible psychological effects of occupying an isolation room; (3) Based on in-depth reviews of the previous two stages, the study then developed further into the design proposal. The IRH design is presented in two parts, namely the unit design and the probable implementation scenario. In particular, the design insinuates the potential for a modular construction approach for addressing the physical isolation space requirements, the needs for quick construction, and the possible applicability to various contexts, especially in the rural regions.

\section{Design Approaches for Accommodating a Surge in Patients}

\subsection{Approaches for Extending Capacity}

Pandemics force governments to increase the number and ease of access to health-care facilities (Berawi, 2020). Consequently, hospitals are required to take measures to expand their capacity through various methods, including repurposing spaces within the hospitals' buildings (Shu et al., 2020), adapting spaces from other public facilities (Yuen et al., 2012), or building entirely new structures (Mo, 2020). The repurposing of existing spaces within hospital buildings is ikely to be done using daptable spaces (Valipoor et al., 2020); however, to do so is challenging for hospitals that do not have such adaptability in its original designs (Carenzo et al., 2020). In the latter case, the option to utilize spaces outside the hospital building is recommended (Blavin and Arnos, 2020; Chen et al., 2020). Moreover, extending isolation spaces outside of the hospitals' buildings could also act as an early measure to prevent possible in-hospital transmission (Chen and Zhao, 2020). Isolation spaces outside of the hospital building ease the burden of the hospitals when performing triage and responding to the patients' condition case by case (Carenzo et al., 2020). This has been evidenced in China (Baldwin, 2020; Shu et al., 2020) and the Philippines (Harrouk, 2020).

Installing additional isolation space by repurposing existing buildings, such as stadiums or exhibition spaces, needs to be completed in as short a period of time as possible (Chen et al., 2020; Mo, 2020). Unfortunately, repurposing existing infrastructure is a privilege reserved for more developed areas. This option is less feasible in rural areas in underdeveloped and developing countries, such as Indonesia, due to the lack of such 
infrastructure; thus, the option of building new isolation facilities is considered more appropriate.

An exemplary proposed design for new additional isolation spaces is a design that utilizes shipping containers. The design incorporates the containers as either new structures completely detached from the hospital buildings (Baldwin, 2020; Mo, 2020) or by installing them in another building as in the design of CURA by Carlo Rattidemonstrating a hybrid approach combined with repurposing of existing structures (Harrouk, 2020). Nonetheless, the practice of utilizing shipping containers reflects a modular construction system, which offers the advantage of accelerating construction and reducing the cost. In this way, the modular system offers a feasible option for countries or areas with fewer resources.

\subsection{A Modular Design Approach for Responding Emergency Situations}

Modular construction systems have many characteristics amenable to a pandemic situation. In general, a modular system is reputable for its short construction period that reduces construction cost considerably (Isaac et al., 2014; Lawson et al., 2014; Ahn and Kim, 2014). In a pandemic situation, low-cost and quick construction is desired for reducing the hospitals' excessive workload. Hospitals can also allocate the excessive cost to other essential health-care expenditures. Moreover, modular construction systems offer flexibility and adaptability (Isaac et al., 2014). A modular construction approach is also well-known for its subsystem that is amenable to the sequential addition of several elements or units (Staib et al., 2008). Therefore, a variety of room functions could still be accommodated even with similar structures (Smith, 2010). When applied to isolation facilities, the elements and units of design allow for flexibility and adaptability to fit within various contexts, as well. In addition, the element and units can be designed to meet standard isolation space requirements as the approach begins with a conscious understanding of the material properties and applicability (Yatmo et al., 2020a).

Another benefit of adopting a modular construction approach in the installation of isolation spaces is the minimum disruption to patient care (Smith, 2010). A retrospective with the aim of adding to hospital capacity in a pandemic, points to the last factor becomes important. Less disruption, especially in the form of noise, means less distraction to the health-care staff and the patients (Ampt et al., 2008).

Overall, the above discussions suggest opportunities and challenges for exploring adaptable isolation spaces to respond to the pandemic. The study in this paper offers a better understanding of how architecture, design, and construction can contribute to supporting health-care services in the event of an emergency. In particular, the exploration of an adaptable isolation space that is detached from the hospital building that lends feasible applications to ease the hospital workload during the emergency, provide an opportunity to prevent a hospital outbreak, is quick to construct, and can be installed in various contexts, especially in less resourceful regions of developing or underdeveloped countries.

\section{Design Criteria for Isolation Facilities}

There are at least three criteria for installing isolation spaces for patients with mild-tomoderate conditions in the event of a pandemic. First, generally, in the time of an outbreak or pandemic, it is always recommended for all patients to be placed in a single isolation room (Kilpatrick et al., 2008). However, installing single isolation rooms can be costly and not feasible in the event of a patient surge. As a consequence, the initial measure taken by hospitals is to cluster patients appropriately based on their conditions (Kilpatrick et al., 2008). Many countries have taken this measure during the COVID-19 pandemic (Carenzo 
et al., 2020; Chen et al., 2020; Phua et al., 2020; Shu et al., 2020). Patients with moderate conditions can be placed in single rooms, as this type of isolation space has been observed to improve patient care and result in a shorter length of stay (Chaudhuryvet al., 2005). Meanwhile, those with mild conditions can be placed within shared rooms. This measure is to control the interaction and reduce patient-to-patient transmission (Atkinson et al., 2009). Nevertheless, providing additional isolation spaces with a variety of room types will help hospitals to better manage their patients in the time of a pandemic, hence providing better care.

Second, the isolation room for patients, even for patients with only mild-to-moderate conditions, has to comply with the air circulation standards of typical isolation rooms (Chen and Zhao, 2020). It is crucial to maintain air pressure (positive, negative, or alternating pressure) and air flow, as well as providing an anteroom and ventilation, either naturally, mechanically, or through hybrid measures (Atkinson et al., 2009; Yuen et al., 2012). Controlling the air pressure and air change rate would help the control of airflow within the room, hence reducing possible airborne infection (Yatmo et al., 2018). Notably, natural ventilation is the least costly, hybrid ventilation is the most suitable for variable weather conditions, and mechanical ventilation is the easiest way to achieve the desired air circulation standard despite also being the most expensive (Atkinson et al., 2009). Of the three types of ventilation, hybrid ventilation seems to be the most suitable type to apply to emergency isolation space in less resourceful hospitals or health-care facilities. Hybrid ventilation mainly depends on natural forces and only use mechanical help when the airflow rate is scarce (Atkinson et al., 2009), which means the cost would not be as high as using full mechanical ventilation.

Third, isolation spaces are notorious for giving psychological effects to the patients (Purssell et al., 2020). A pandemic possibly means a longer length of stay in isolation, which is why consideration of the psychological effects of being isolated also needs to be addressed in the design. To promote the feeling of being connected to the outside world, the design should provide access to the outside, either through visual access or direct physical access.

In addition to those three main criteria, additional isolation spaces provided outside the hospitals' buildings need to have controlled access to the main hospitals' buildings (Mitchell et al., 2017; Valipoor et al., 2020). The additional facilities should also comply with the requirements for access to patient or logistics transport (Carenzo et al., 2020) to ensure appropriate services for isolated patients.

\section{Isolation Recovery House (IRH) Design Proposal}

\subsection{Development of IRH units}

Based on the above minimum criteria, the study proposes the design of adaptable isolation spaces. Our development culminated in a set of designs for modular isolation units, termed an Isolation Recovery House (IRH). The IRH consists of seven units, namely a Patient House Type 1, Patient House Type 2, Patient House Type 3, a Health-care Staff House, a Health-care Coordination House, a corridor, and toilets (as an adjacent unit to the Patient House type 3).

The Patient Houses are differentiated into three types based on the number of beds and type of room provided by each unit. Patient House Type 1 has two single-bed rooms, Patient House Type 2 has one room with three beds, and Patient House Type 3 has one room with six beds. However, only Patient Houses Type 1 and 2, have one toilet facility within each room. The Patient Houses meet the minimum isolation space criteria for hospitals, such as a bed, a table, a hybrid ventilation system (spot AC, exhaust fan, and windows) for cross- 
flow air circulation (Atkinson et al., 2009), an emergency button, and an electricity bar for medical equipment. Exhaust fans are provided to control the air circulation in the room by maintaining negative pressure (Ulrich et al., 2008) and placed near a patient's head in the bed to make sure that the air exhaled by the patient goes directly outside the room (Jacob et al., 2019). Windows are also installed to make sure that the patients can look outside of the room (Connellan et al., 2013), hence reducing anxiety. This is particularly important in Patient House Type 1, where patients are assigned single-bed rooms. The other two Patient House types also have windows, but as the room is not used privately, patients still have interaction with other patients. Nonetheless, a shared room is provided with replaceable curtains-for sanitary purposes (Mitchell et al., 2017)-to uphold patient privacy (Connellan et al., 2013).

As the proposed facilities are separated from the main hospital building, the IRH design supports spaces that can act as an extension of hospital care and control, namely the Healthcare Staff House and the Health-care Coordination. The Healthcare Staff House provides a space for health-care staff in charge to rest between their shifts. A transitional space for decontamination is designed for this unit, where the staff wear and take off the protection device before getting to and out from the isolation house units. Meanwhile, the Health-care Coordination House provides a space for preparing medical and non-medical treatments and for storing medical equipment and supplies (Mitchell et al., 2017).

The IRH design consists of modular units constructed from certain components. All the unit types share similar materials that are easy to get even in remote regions. The material components are carefully calculated into the design to ensure minimum handling processes during construction, hence minimizing the construction period. For example, the IRH units use fiber-cement boards as the wall components that require almost no cut. Even the door is designed to fit within the size of the wall. In this way, the IRH design allows for duplication, requires less construction jobs, hence minimizing construction error, and construction can be finished in a short time. The calculation of material components also considers how the material can be used within the unit, hence reducing construction waste. Overall, the design ensures compliance with infection control requirements. In addition to a variety of isolation room types and the application of negative pressure and hybrid ventilation, the design also applies an easy-to-clean coating material to its walls, floors, and ceilings, hence easing the cleaning measures (Mitchell et al., 2017) and minimizing the transmission through hand touches (Yatmo et al., 2020b).
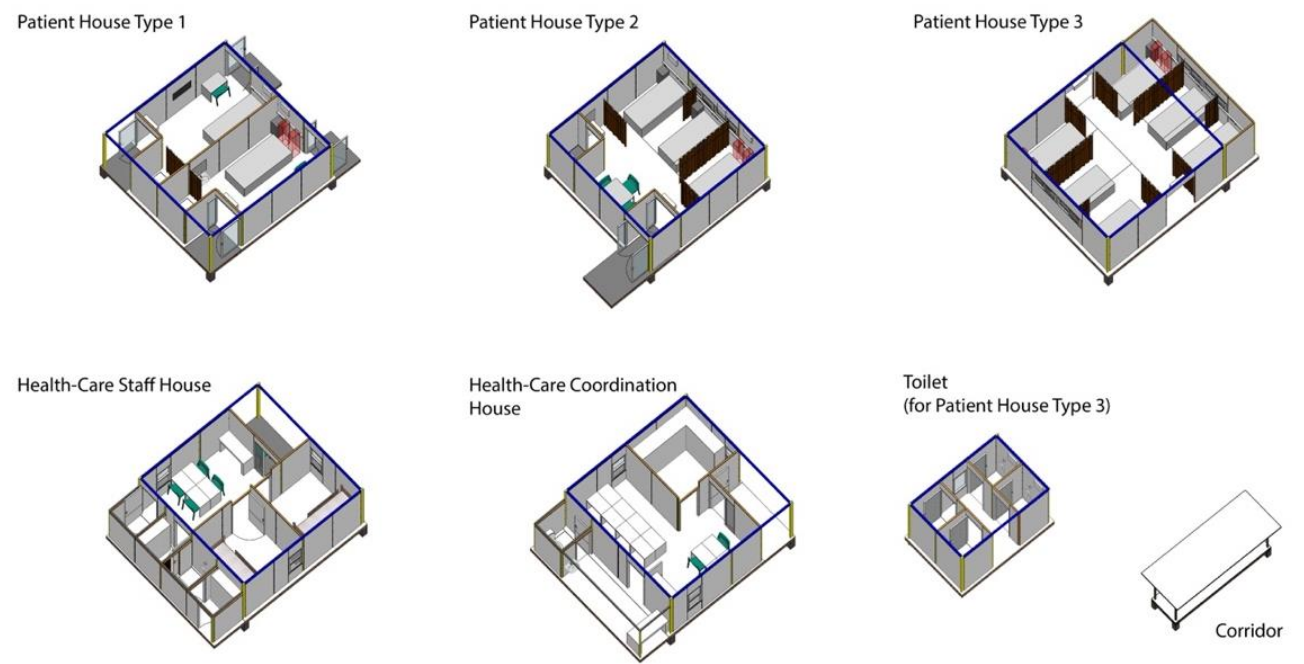

Figure 1 IRH modular units 

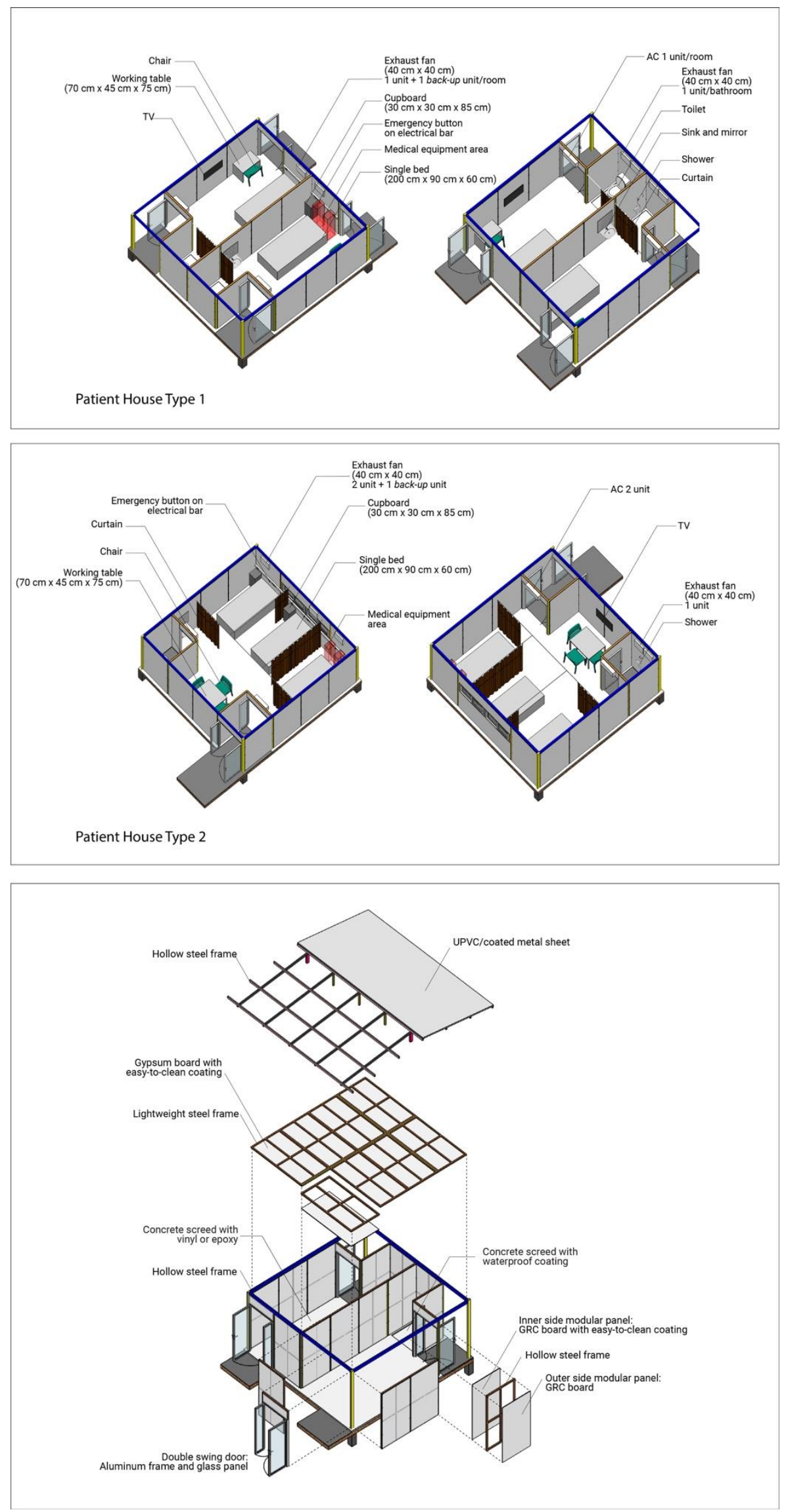

Figure 2 Top and middle: Amenities in the Patient House Type 1, Patient House Type 2. Bottom: Material components in a unit 


\subsection{Possible Scenarios for Implementing IRH}

The IRH offers two kinds of adaptability: by responding to various contexts and needs, and by anticipating the future utilization of the modular components when the pandemic ends. The first kind of adaptability is achieved through the variety of IRH units. There are three types of primary units, the Patient House unit where the patients are taken care of, the Health-Care Staff House unit where the health-care staff can work and take a break, and the Health-care Coordination House unit where the health-care services are prepared. There are also three types of Patient House units which add to the variety of the unit configuration possibilities. These units allow the hospital to choose and combine the types of units to install as an extension of their existing hospital facilities.

By offering different types of units, the IRH design caters to various implementation scenarios as illustrated in Figure 3. The best scenario for implementing the IRH design is one which uses the Patient House Type 1, the Health-Care Staff House, and the Health-care Coordination House. Such a scenario is suitable for hospitals that need isolation space for patients with moderate conditions. In other scenarios, the selected units can include the Patient House Type 2, a Health-Care Staff House, and a Health-Care Coordination House. The difference between the two scenarios lies in the chosen patients' isolation room, as in this scenario, the IRH implements the use of shared isolation rooms, which are more suitable for patients with mild conditions. Meanwhile, in case the hospitals only need space for patients in mild conditions and for those who are about to recover fully but still need monitoring before being discharged, a scenario that incorporates Patient House Type 3 and a Health-care Coordination House is available.

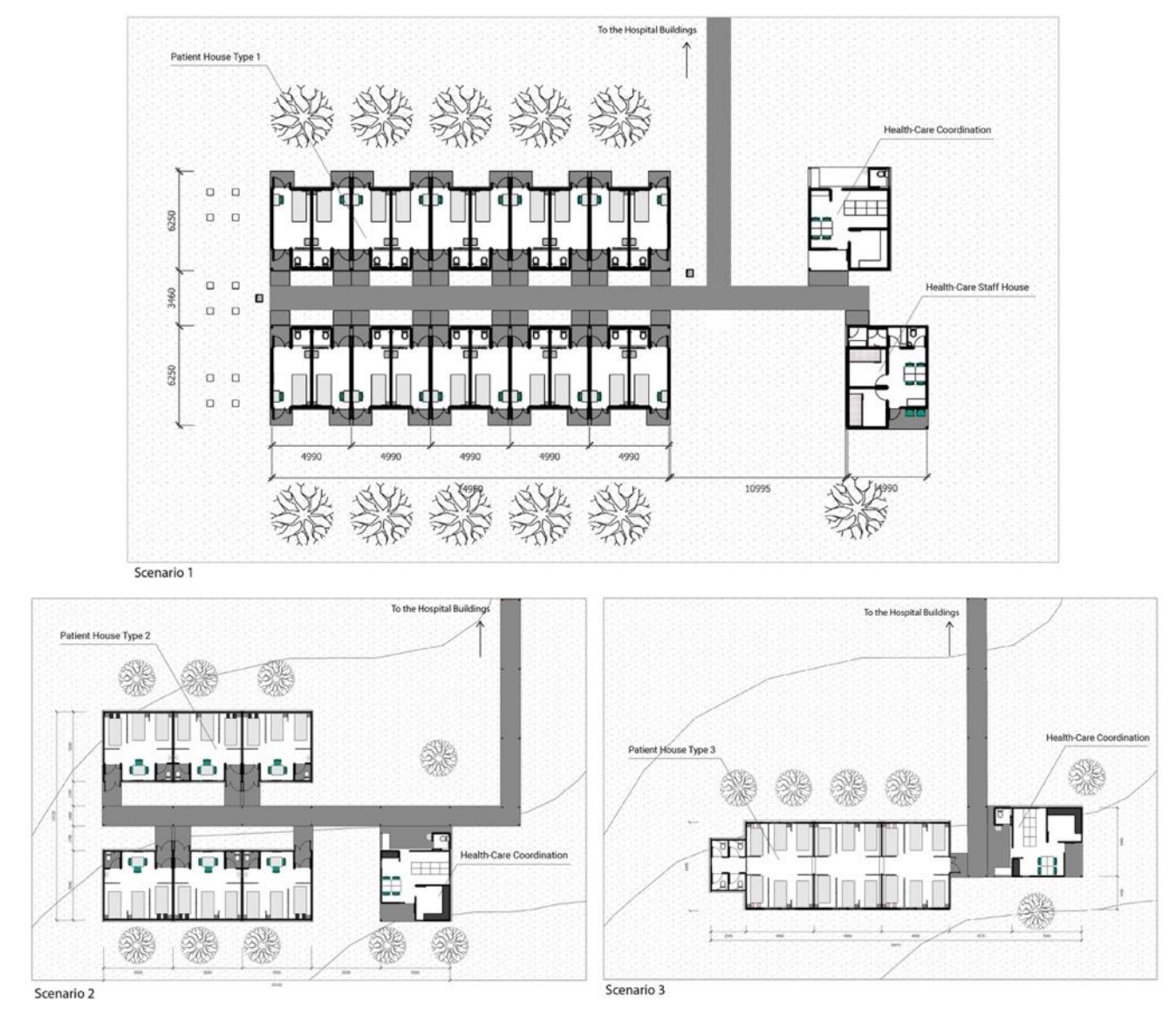

Figure 3 Alternative scenarios of IRH implementation 
In these scenarios, Patient Houses can either be adjacent or independent, hence allowing the IRH to fit in with the site upon which it is going to be installed. These scenarios also show how the Patient Houses are grouped, and placed separately from the Health-Care Staff House and the Health-Care Coordination House. This is important for minimizing the possible occurrence of patient-to-staff transmission (Phua et al., 2020). All of the units are connected by a corridor that accesses the main hospital building.

The second quality of the IRH design lies in the future use of the units after the pandemic ends. As the modular components of IRH units are designed with careful consideration of the material in use, in a sense that it maintains the original size and condition of the materials, all of the material can be disassembled and stored for future use when another major emergency occurs (Ahn and Kim, 2014). It is also possible that the disassembled material components are brought to other locations and used for entirely different purposes, such as classrooms, communal kitchens, or other emergency or nonemergency functions.

\section{Conclusions}

The study has proposed the Isolation Recovery House (IRH), a design of adaptable isolation units that is applicable to various contexts in a pandemic or other major healthcare situations. Through careful compilation of the minimum criteria for installing isolation spaces and modular construction systems, the study furnishes a design that responds to the need for providing additional isolation space for hospitals, health-care facilities, or other institutions with limited resources. This study positioned the IRH as a possible low-tech isolation space that does not neglect the minimum standards required of isolation space. Moreover, the modular system incorporated in the design not only offers the opportunity for fast construction and the ability to fit in various contexts, but it can also be disassembled for post-pandemic usage. However, like other health-care facilities, the IRH needs to be accompanied by other isolation and health-care measures when implemented, such as clinical procedures, cleaning procedures, and standards for staff safety.

The study presented in this paper particularly contributes to the architectural design practice of the health-care environment in the event of an emergency. Emergency healthcare situations, such as a pandemic, force countries to take drastic measures to respond to hospital surges that can be costly despite the resource gap among the countries or areas within those countries that affects the extension of measures a hospital can take (Blavin and Arnos, 2020). Nevertheless, many of the emergency facilities cannot meet the resource constraint these areas have. In particular, the study adds insight into a possible low-tech health-care facility that is not only quick to construct but also relevant to those areas with limited resources.

The proposed IRH design is open to further development for more robust implementation both in the current COVID-19 pandemic and for other possible future needs. It is necessary to conduct further investigations that look closely at how the IRH is implemented. Therefore, the quick construction and aspects of adaptability and flexibility of the IRH design proposal would be verified. A study assessing aspects revolving around the performance of the isolation space, such as a simulation study which visualizes the airflow within the IRH units, would be highly beneficial as way to ensure the performance of health-care through computational approach (Johanes et al., 2015). Further research on various systems to support the design in tackling the impact of the pandemic, such as food and medicine distribution, infection control, and the advancement of information technology (Berawi et al., 2020) is also necessary. Integration of the proposed design into relevant systems is essential to achieving the design purpose. 


\section{Acknowledgements}

This research is supported by Penelitian Dasar Ristek-BRIN 2020, a research grant provided by the Ministry of Research and Technology of the Republic of Indonesia.

\section{References}

Ahn, Y.H., Kim, K.-T., 2014. Sustainability in Modular Design and Construction: A Case Study of 'The Stack'. International Journal of Sustainable Building Technology and Urban Development, Volume 5(4), pp. 250-259

Ampt, A., Harris, P., Maxwell, M., 2008. The Health Impacts of the Design of Hospital Facilities on Patient Recovery and Wellbeing, and Staff Wellbeing: A Review of the Literature. Centre for Primary Health Care and Equity, University of New South Wales

Atkinson, J., Chartier, Y., Pessoa-Silva, C.L., Jensen, P., Li, Y., Seto, W.-H. (Eds.)., 2009. Natural Ventilation for Infection Control in Health-Care Settings. World Health Organization.

Baldwin, E., 2020. China Completes Hospital in 10 Days to Fight Coronavirus. Archdaily. Available Online at https://www.archdaily.com/933080/china-completes-hospitalin-10-days-to-fight-wuhans-coronavirus, Accessed on May 4, 2020

Berawi, M.A., 2020. Empowering Healthcare, Economic, and Social Resilience during Global Pandemic COVID-19. International Journal of Technology, Volume 11(3), pp. 436-439

Berawi, M. A., Suwartha, N., Kusrini, E., Yuwono, A.H., Harwahyu, R., Setiawan, E.A., Yatmo, Y.A., Atmodiwirjo, P., Zagloel, Y.T., Suryanegara, M., Putra, N., Budiyanto, M.A., Whulanza, Y., 2020. Tackling the COVID-19 Pandemic: Managing the Cause, Spread, and Impact. International Journal of Technology, Volume 11(2), pp. 209-214

Blavin, F., Arnos, D., 2020. Hospital Readiness for COVID-19: Analysis of Bed Capacity and How It Varies Across the Country. Robert Wood Johnson Foundation. Available Online at https://www.rwjf.org/en/library/research/2020/03/hospital-readiness-forcovid19-analysis-of-bed-capacity-and-how-it-varies-across-the-country-html, Accessed on May 3, 2020

Becker, F., Parsons, K.S., 2007. Hospital Facilities and the Role of Evidence-based Design. Journal of Facilities Management, Volume 5(4), pp. 263-274

Carenzo, L., Costantini, E., Greco, M., Barra, F.L., Rendiniello, V., Mainetti, M., Bui, R., Zanella, A., Grasselli, G., Lagioia, M., Protti, A., Cecconi, M., 2020. Hospital Surge Capacity in a Tertiary Emergency Referral Centre during the COVID-19 Outbreak in Italy. Anaesthesia, Volume 75(7), pp. 928-934

Chaudhury, H., Mahmood, A., Valente, M., 2005. Advantages and Disadvantages of SingleVersus Multiple-Occupancy Rooms in Acute Care Environments: A Review and Analysis of the Literature. Environment and Behavior, Volume 37(6), pp. 760-786

Chen, C., Zhao, B., 2020. Makeshift Hospitals for COVID-19 Patients: Where Health-Care Workers and Patients Need Sufficient Ventilation for More Protection. Journal of Hospital Infection, Volume 105(1), pp. 98-99

Chen, S., Zhang, Z., Yang, J., Wang, J., Zhai, X., Bärnighausen, T., Wang, C., 2020. Fangcang Shelter Hospitals: A Novel Concept for Responding to Public Health Emergencies. The Lancet, Volume 395(10232), pp. 1305-1314

Connellan, K., Gaardboe, M., Riggs, D., Due, C., Reinschmidt, A., Mustillo, L., 2013. Stressed Spaces: Mental Health and Architecture. HERD: Health Environments Research \& Design Journal, Volume 6(4), pp. 127-168

Harrouk, C., 2020. WTA Design 60 Emergency Quarantine Facilities to Fight COVID-19. Archdaily. Available Online at https://www.archdaily.com/937563/wta-design-60emergency-quarantine-facilities-to-fight-covid-19, Accessed on May 4, 2020 
Isaac, S., Bock, T., Stoliar, Y., 2014. A New Approach to Building Design Modularization, Procedia Engineering, Volume 85, pp. 274-282

Jacob, S., Yadav, S.S., Sikarwar, B.S., 2019. Design and Simulation of Isolation Room for a Hospital. In: Saha P., Subbaro P., Sikarwar B. (eds.), Advances in Fluid and Thermal Engineering. Lecture Notes in Mechanical Engineering, pp. 75-93

Johanes, M., Yatmo, A.Y., Atmodiwirjo, P., 2015. The Use of Computational Medium for Visualization and Simulation in Healthcare Architectural Design. In: $20153^{\text {rd }}$ International Conference on New Media (CONMEDIA), pp. 1-6

Kilpatrick, C., Prieto, J., Wigglesworth, N., 2008. Single Room Isolation to Prevent the Transmission of Infection: Development of a Patient Journey Tool to Support Safe Practice. British Journal of Infection Control, Volume 9(6), pp. 19-25

Lawson, M., Raymond, O., Goodier, C. (Eds.), 2014. Design in Modular Construction. CRC Press.

Mitchell, B.G., Williams, A., Wong, Z., O’Connor, J., 2017. Assessing a Temporary Isolation Room from an Infection Control Perspective: A Discussion Paper. Infection, Disease \& Health, Volume 22(3), pp. 129-135

Mo, M., 2020. A Closer Look at the Chinese Hospitals Built to Control the COVID-19 Pandemic. Archdaily. Available Online at https://www.archdaily.com/937579/acloser-look-at-the-chinese-hospitals-built-to-control-the-covid-19-pandemic, Accessed on May 4, 2020

Nwanya, S.C., Sam-Amobi, C., Ekechukwu, O.V., 2016. Energy Performance Indices for Hospital Buildings in Nigeria. International Journal of Technology, Volume 7(1), pp. 1525

Phua, J., Weng, L., Ling, L., Egi, M., Lim, C.-M., Divatia, J.V., Shrestha, B.R., Arabi, Y.M., Ng, J., Gomersall, C.D., Nishimura, M., Koh, Y., Du, B., 2020. Intensive Care Management of Coronavirus Disease 2019 (COVID-19): Challenges and Recommendations. The Lancet Respiratory Medicine, Volume 8(5), pp. 506-517

Purssell, E., Gould, D., Chudleigh, J., 2020. Impact of Isolation on Hospitalised Patients Who are Infectious: Systematic Review with Meta-Analysis. BMJ Open, Volume 10(2), pp. 18

Shu, L., Ji, N., Chen, X., Feng, G., 2020. Ark of Life and Hope: Role of Cabin Hospital in Facing COVID-19. Journal of Hospital Infection, Volume 105(2), pp. 351-352

Smith, R.E., 2010. Prefab Architecture: A Guide to Modular Design and Construction. USA: John Wiley \& Sons

Staib, G., Dörrhöfer, A., Rosenthal, M.J., 2008. Components and Systems: Modular Construction: Design, Structure, New Technologies (1st ed). Edition Detail, Institut für internationale Architektur-Dokumentation, Birkhäuser

Stichler, J.F., Hamilton, D.K., 2008. Evidence-Based Design: What is It? HERD: Health Environments Research \& Design Journal, Volume 1(2), pp. 3-4

Suwartha, N., Ardiyansyah, Berawi, M.A., Surjandari, I., Zagloel, T.Y.M., Atmodiwirjo, P., Yatmo, Y.A., 2017. Science, Technology and Innovation for Sustainable World. International Journal of Technology, Volume 8(6), pp. 979-982

Ulrich, R.S., Zimring, C., Zhu, X., DuBose, J., Seo, H.-B., Choi, Y.-S., Quan, X., Joseph, A., 2008. A Review of the Research Literature on Evidence-Based Healthcare Design. HERD: Health Environments Research \& Design Journal, Volume 1(3), pp. 61-125

Valipoor, S., Hakimjavadi, H., De Portu, G., 2020. Design Strategies to Improve Emergency Departments' Performance During Mass Casualty Incidents: A Survey of Caregivers. HERD: Health Environments Research \& Design Journal, Volume 13(1), pp. 206-220 
Yatmo, Y.A., Putra, N., Harahap, M.M.Y., Saginatari, D.P., 2018. Evaluation of Spatial Layout in Health Care Waiting Areas based on Simulation of Droplet Movement Trace. International Journal of Technology, Volume 9(5), pp. 888-897

Yatmo, Y.A., Atmodiwirjo, P., Saginatari, D.P., Harahap, M.M.Y., 2020a. Development of Modular School Design as a Permanent Solution for Post-Disaster Reconstruction in Indonesia. International Journal of Disaster Resilience in the Built Environment, Volume 12(1), pp. 101-113

Yatmo, Y.A., Atmodiwirjo, P., Harahap, M.M.Y., 2020b. Hand Touches on the Surfaces of a Healthcare Waiting Area. Journal of Hospital Infection, Volume 105(2), pp. 383-385

Yuen, P.L., Yam, R., Yung, R., Choy, K.L., 2012. Fast-track Ventilation Strategy to Cater for Pandemic Patient Isolation Surges. Journal of Hospital Infection, Volume 81(4), pp. 246250 